Movere Journal Vol 2 No. 2 Juli 2020 Hal 1-8

MOVERE JOURNAL

http://ojs.stie-tdn.ac.id/index.php/mv

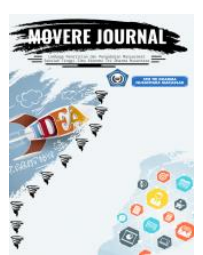

\title{
PENGARUH SELEKSI TERHADAP KINERJA KARYAWAN PADA PT. TRANS RETAIL INDONESIA CARREFOUR PANAKUKANG MAKASSAR
}

\author{
Ady Andardinata \\ Andi Nonong Sunrawali \\ Dian Setiawan
}

STIE Tri Dharma Nusantara Makassar

\begin{abstract}
Abstrak: Pengaruh Seleksi Terhadap Kinerja Karyawan pada PT. Trans Retail Indonesia Carrefour Panakukang Makassar.Penelitian ini bertujuan untuk mengetahui pengaruh seleksi terhadap kinerja karyawan pada PT. Trans Retail Indonesia Carrefour Panakukang Makassar.Sumber data dalam penelitian ini adalah data primer dan sekunder.Metode analisis yang digunakan adalah analisis deskriptif dan analisis statitistik dengan beberapa teknik analisa melalui pemanfaatan Statistical Package for Social Science (SPSS) versi 17.0 for Windows antara lain, uji regresi linier sederhana,koefisien korelasi,koefisien determinasi dan uji $\mathrm{t}$, dimana $\mathrm{y}=26,531+0,389 \mathrm{X}, \mathrm{r}=0,487, \mathrm{r}^{2}=0,237(23,7 \%)$, $\mathrm{t}$ hitung $=4,056$ dan $\mathrm{t}$ tabel $=1,674$. Dari hasil penelitian ini diperoleh nilai $\mathrm{t}$ hitung lebih besar dari nilai t tabel $(3,983>1,674)$ pada taraf nyata $0,05(5 \%)$. Dengan demikian $\mathrm{H}_{0}$ ditolak dan menerima $\mathrm{H}_{\mathrm{a}}$, artinya seleksi berpengaruh postif dan signifikan terhadap kinerja karyawan pada PT. Trans Retail indonesia Carrefour Panakukang Makassar.Dengan demikian hipotesis diterima.
\end{abstract}

\section{Kata kunci : Seleksi, kinerja}

\section{PENDAHULUAN}

\section{Latar Belakang}

Sumber Daya Manusia merupakan salah satu faktor yang paling berpengaruh terhadap maju mundurnya suatu perusahaan,oleh karena itu bisa dipastikan bahwa setiap organisasi selalu

Corresponding Author: adyandardinata173@gmail.com ingin mendapatkan sumber daya manusia yang memiliki kinerja yang bagus sehingga dapat mewujudkan apa yang menjadi tujuan yang telah direncanakan oleh suatu perusahaan atau organisasi.

Dengan adanya seleksi yang dilakukan oleh perusahaan dalam perekrutan karyawan diharpakan mampu

(C) 2020 STIE TDN. All rights reserved 
meminimalisir dari kesalahan dalam mendapatkan karyawan yang diinginkan oleh perusahaan. Seleksi karyawan merupakan salah satu cara untuk mendapatkan karyawan yang sesuai kebutuhan perusahaan dan tentunya dengan adanya sistem seleksi tersebut diharapkan perusahaan mendapatkan calon calon karyawan yang memiliki integritas yang tinggi serta memiliki kualitas yang tentunya mampu meningkatkan produktivitas perusahaan.

Secara umum kinerja merupakan hasil kerja yang dicapai seorang karyawan dalam suatu perusahaan. Atau dengan kata lain bahwa kinerja adalah prestasi kerja seseorang. Kinerja karyawan merupakan suatu tindakan yang dilakukan karyawan dalam melaksanakan pekerjaan yang diberikan oleh perusahaan. Setiap perusahaan mengharapkan karyawannya mempunyai prestasi kerja yang tinggi karena dengan karyawan yang berprestasi akan memberikan sumbangan atau kontribusi yang positif bagi kemajuan perusahaan.

Dari uraian diatas maka penulis tertarik untuk melakukan suatu penelitian dengan judul "Pengaruh Seleksi Terhadap Kineja Karyawan Pada PT. Trans Retai Indonesia Carrefour Panakukang Makassar”.

\section{Rumusan Masalah}

Rumusan masalah dalam penelitian ini adalah 'Apakah Seleksi berpengaruh terhadap kinerja karyawan pada PT. Trans Retail Indonesia Carrefour Panakukang Makassar'

\section{Tujuan Penelitian}

Untuk mengetahui pengaruh seleksi terhadap kinerja karyawan pada PT. Trans Retail Indonesia Carrefour

Corresponding Author: adyandardinata173@gmail.com

\section{Panakukang Makassar’}

\section{Kegunaan Penelitian}

1. Sebagai bahan informasi sekaligus pertimbangan bagi pihak manajemen dan pimpinan dalam usaha meningkatkan kinerja karyawan

2. Dapat menjadi bahan acuan atau referensi bagi penulis lainnya yang akan melakukan penelitian dengan judul yang sama.

\section{TINJAUAN PUSTAKA}

\section{Seleksi}

Menurut Kasmir (2017:100): 'Seleksi merupakan kegiatan lanjutan dari rekrutmen yang sudah dilakukan sebelumnya. Artinya hasil rekrutmen yang dilakukan oleh perusahaan kemudian dipilih untuk menentukan mana yang layak atau memenuhi kualifikasi yang diharapkan. Layak maksdunya adalah memenuhi persyaratan yang telah ditetapkan dan sesuai dengan standar yang ditetapkan perusahaan'.

Sedangkan Andrew dalam Mangkunegara (2016:35): seleksi adalah pemilihan. Menyeljsi merupakan suatu pengumpulan dari suatu pilihan. Proses seleksi melibatkan pilihan dari berbagai objek dengan mengutamakan beberapa objek saja yang dipilih'.

Dari pengertian diatas dapat disimpulkan bahwa Seleksi adalah proses rekrutmen yang dilakukan oleh suatu perusahaan dalam mencari caloncalon karyawan secara objektif untuk ditempatkan pada posisi-posisi atau bagian-bagian yang dibutuhkan oleh perusahaan. 


\section{Kinerja}

Sedarmayanti (2011:181) mengatakan bahwa "kinerja merupakan hasil kerja atau kemampuan kerja yang diperlihatkan seseorang,sekelompok orang, (organisasi) atas suatu pekerjaan pada waktu tertentu". Sedangkan Mangkunegara (2016:67) menyatakan bahwa 'kinerja karyawan (prestasi kerja) adalah hasil kerja secara kualitas dan kuantitas yang dicapai oleh seseorang karyawan dalam melaksanakan tugasnya sesuai dengan tanggung jawabyang diberikan kepadanya'.

Dapat disimpulkan bahwa kinerja adalah hasil kerja yang dicapai seorang individu,kelompok dalam suatu organisasi atau perusahaan setelah menyelesaikan suatu pekerjaan yang diberikan oleh organisasi atau perusahaan dalam waktu tertentu.

\section{Kerangka Pikir}

\section{Gambar 1: Kerangka pikir}

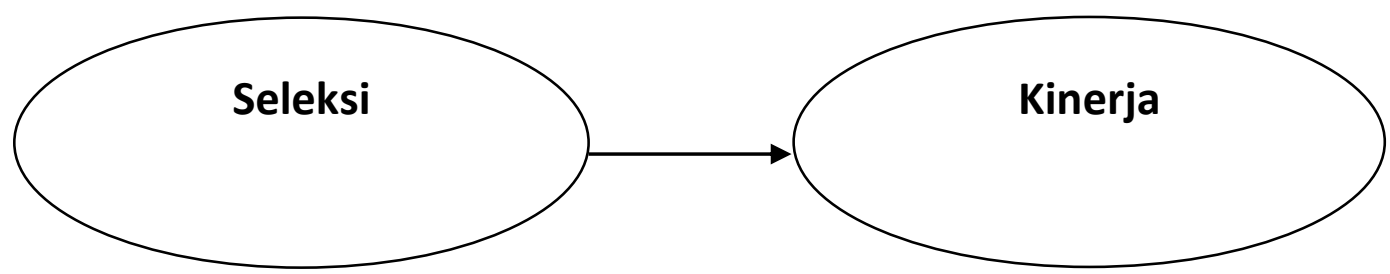

\section{Sumber: Data diolah}

\section{Hipotesis}

Berdasarkan latar belakang dan rumusan masalah maka hipotesis dalam penelitian ini adalah diduga bahwa seleksi berpengaruh positif dan signifikan terhadap kinerja karyawan pada PT.Trans Retail Indonesia Carrefour Panakukang Makassar.

\section{METODE PENELITIAN}

\section{Metode Pengumpulan Data}

Metode yang digunakan dalam pengumpulan adalah sebagai berikut:

1. Observasi, yaitu melakukan pengamatan langsung pada obyek yang diteliti dalam hal ini adalah PT. Trans Retail Indonesia

Corresponding Author: adyandardinata173@gmail.com
Carrefour Panakukang Makassar.

2. Kuesioner, yaitu teknik pengumpulan data yang dilakukan dengan cara memberikan seperangkat pertanyaan atau pernyataan secara tertulis kepada responden untuk dijawab.

3. Wawancara, yaitu merupakan pertemuan atau melakukan pembicaraan secara langsung untuk memperoleh informasi dengan pihak yang terkait dalam hal ini adalah karyawan PT. Trans Retail indonesia Carrefour Panakukang Makassar

\section{Jenis dan Sumber Data}

1. Jenis data yang digunakan dalam penelitian ini adalah:

(C) 2020 STIE TDN. All rights reserved 
a) Data kualitatif, yaitu data yang diperoleh dari instansi dalam bentuk informasi baik secara lisan maupun tulisan atau dengan kata lain yang sifatnya deskriptif.

b) Data kuantitaf, yaitu data yang diperoleh dari kantor berupa dalam bentuk angka laporan.

2. Sumber data yang digunakan dalam penelitian ini ada adalah

a) Data primer adalah data yang diperoleh secara langsung dari sumber aslinya. Data primer ini diperoleh melalui hasil pengamatan dan melalui koesioner yang dibagikan.

b) Data Sekunder adalah data yang dikumpulkan secara tidak langsung dari sumbernya. Data sekunder ini diperoleh melalui dokumen yang ada dalam kantor serta berbagai literatur bahan kuliah yang berkaitan dengan penelitian ini.

\section{Populasi dan Sampel}

1. Populasi

Menurut Sugiyono

"Populasi adalah wilayah generalisasi yang terdiri atas obyek/subyek yang mempunyai kuantitas dan karakteristik tetentu yang ditetapkan oleh peneliti untuk dipelajari dan kemudian ditarik kesimpulannya". Jumlah populasi yang digunakan dalam penelitian ini adalah seluruh karyawan pada PT.Trans Retail indonesia Carrefour Panakukang Makassar dengan jumlah populasi sebanyak 55 orang.

\section{Sampel}

Jumlah sampel dalam penelitian ini adalah 55 orang,dimana 55 orang ini adalah seluruh jumlah karyawan pada

Corresponding Author: adyandardinata173@gmail.com
PT. Trans Retail Indonesia Carrefour Panakukang Makassar yang menjadi responden dalam penelitian ini.

\section{Metode Analisis Data}

Metode analisis data yang dipergunakan dalam penelitian ini adalah analisis deskriptif dan analisis statistik dengan menggunakan beberapa teknik analisa melalui pemanfaatan Statistical Package for Social Science (SPSS) versi 17.0 for Windows antara lain adalah : Analisis regresi linear sederhana, koefisien korelasi, koefisien determinasi dan uji $\mathrm{t}$

1. Analisis Deskriptif

Analisis deskriptif dalam penelitian ini meliputi analisis karakteristik responden, analisis statistik deskriptif tang terdiri dari nilai maksimal,minimal,mean, dan standar deviasi,serta kategorisasi jawaban responden. Deskriptif variabel penelitian menggambarkan tanggapan responden mengenai pengaruh seleksi terhadap kinerja karyawan PT. PT. Trans Retail Indonesia Carrefour Panakukang Makassar.

2. Analisis Statistik

a) Regresi linear sederhana

Analisis regresi linier sederhana adalah metode perhitungan untuk untuk mengetahui pengaruh antara variabel $\mathrm{X}$ (Seleksi) terhadap variabel Y (Kinerja). Persamaan umum regresi linier sederhana adalah :

$\mathrm{Y}=\mathrm{a}+\mathrm{b}(\mathrm{x})$

Dimana:

$\mathrm{Y}=$ Kinerja

$\mathrm{X}=$ Seleksi

$\mathrm{a}=$ Konstanta

$\mathrm{b}=$ Koefisien regresi

Untuk memperoleh nilai $a$ dan $b$ (C) 2020 STIE TDN. All rights reserved 
dapat ditentukan dengan rumus sebagai berikut :

$$
\begin{array}{r}
b=\frac{n \sum x y-\left(\sum x\right)\left(\sum y\right)}{n \sum x^{2}-\left(\sum x\right)^{2}} \\
a=\frac{\sum y}{n}-b \frac{\sum x}{n}
\end{array}
$$

b) Uji Korelasi (r)

Koefisien korelasi (r) bertujuan untuk mengetahui keterkaitan antara variabel $\mathrm{X}$ dan variabel $\mathrm{Y}$. Adapun bentuk formula umum dari koefisien korelasi adalah

$$
=\frac{n \sum x y-\left(\sum x\right)\left(\sum y\right)}{\sqrt{\left\{n \sum x^{2}-\left(\sum x^{2}\right)\right\}} \cdot\left\{n \sum y^{2}-\left(\sum y^{2}\right)\right\}}
$$

Tabel 1 : Pedoman interprestasi koefisien korelasi ( $\mathrm{r}$ )

\begin{tabular}{|c|c|}
\hline Interval & Kriteria \\
\hline $0,00-0,19$ & Sangat Lemah \\
\hline $0,20-0,39$ & Lemah \\
\hline $0,40-0,59$ & Sedang \\
\hline $0,60-0.79$ & Kuat \\
\hline $0,80-1,00$ & Sangat Kuat \\
\hline
\end{tabular}

Dimana ;

$$
\mathrm{n} \quad=\text { responden }
$$

$\mathrm{r} \quad=\quad$ Koefisien

korelasi

$\mathrm{X}$ dan $\mathrm{Y}=$ nilai dalam variabel $\mathrm{X}$ dan $\mathrm{Y}$

$\mathrm{X}^{2}$ dan $\mathrm{Y}^{2}=$ Nilai perkalian dalam variabel $\mathrm{X}$ dan $\mathrm{Y}$

$\mathrm{XY}=$ perkalian dari skor dalam variabel $\mathrm{X}$ dan $\mathrm{Y}$

Untuk mengukur interval keeratan hubungan, digunakan standar pengukuran korelasi sebagai berikut : c) Koefisien Determinasi $\left(\mathrm{r}^{2}\right)$

Dalam analisis regresi agar koefisien korelasi yang diperoleh dapat diartikan maka dihitung indeks determinasinya, yaitu hasil kuadrat dari koefisien korelasi:

$$
r_{x y}^{2}=\left(r_{x y}\right)^{2}
$$

Indeks determinasi yang diperoleh tersebut digunakan untuk menjelaskan persentase variasi dalam variabel tidak bebas (Y) yang disebabkan oleh bervariasinya variabel bebas $(\mathrm{X})$.

d) Uji t

Uji t digunakan untuk melihat tingkat signifikansi antara variabel seleksi (X) terhadap variabel

Corresponding Author: adyandardinata173@gmail.com 
Adapun masing-masing kriteria pengujian hipotesis :

1) Apabila dari hasil perhitungan diketahui $t_{\text {hitung }}>$ $\mathrm{t}_{\text {tabel }}$ maka hipotesis nol $\left(\mathrm{H}_{0}\right)$ di tolak dan hipotesis alternatif $\left(\mathrm{H}_{\mathrm{a}}\right)$ diterima, hal ini berarti bahwa ada pengaruh positif atau signifikan antara seleksi dan kinerja karyawan.

2) Sebaliknya apabila dari hasil perhitungan diketahui $t_{\text {hitung }}<$ $\mathrm{t}_{\text {tabel }}$ maka hipotesis nol $\left(\mathrm{H}_{0}\right)$ diterima dan hipotesis alternatif $\left(\mathrm{H}_{\mathrm{a}}\right)$ ditolak, ini berarti bahwa tidak ada pengaruh yang positif atau signifikan antara seleksi dan kinerja karyawan

Setelah itu, membandingkan nilai statistik $t$ hitung dengan nilai

Tabel 2: Analisis regresi linear sederhana statistik t tabel:

1) Apabila nilai statistik $t$ hitung <nilai statistik t tabel, maka Ho diterima

2) Apabila nilai statistik $t$ hitung > nilai statistik tabel, maka Ho ditolak.

HASIL DAN PEMBAHASAN

Untuk mengetahui pengaruh seleksi terhadap kinerja karyawan maka metode analisis yang digunakan adalah sebagai berikut :

1. Regresi Linear sederhana

Hasil pengujian analisis regresi sederhana untuk mengukur pengaruh seleksi terhadap kinerja karyawan pada PT. Trans Stuidio Indonesia Retail Carrefour Panakukang Makassar dalam bentuk output SPSS 17 seperti pada tabel berikut :

\section{Coefficients $^{\mathrm{a}}$}

\begin{tabular}{|c|c|c|c|c|c|c|}
\hline \multirow{2}{*}{\multicolumn{2}{|c|}{ Model }} & \multicolumn{2}{|c|}{$\begin{array}{c}\text { Unstandardized } \\
\text { Coefficients }\end{array}$} & \multirow{2}{*}{$\begin{array}{c}\begin{array}{c}\text { Standardized } \\
\text { Coefficients }\end{array} \\
\text { Beta }\end{array}$} & \multirow[b]{2}{*}{$\mathrm{t}$} & \multirow[b]{2}{*}{ Sig. } \\
\hline & & B & Std. Error & & & \\
\hline & (Constant) & 26.531 & 3.856 & & 6.880 & .000 \\
\hline & Seleksi & .389 & .096 & .487 & 4.056 & .000 \\
\hline
\end{tabular}

a. Dependent Variable: Kinerja

Sumber: Data Diolah SPSS 17

Dari tabel 2 menunjukkan bahwa persamaan regresi linear sederhananya adalah: $\mathrm{Y}=26,531+0,389 \mathrm{X}$, artinya terdapat pengaruh yang positif antara seleksi terhadap kinerja karyawan pada PT. Trans Retail Indonesia Carrefour Panakukang Makassar.Dimana walaupun tanpa seleksi maka kinerja kerja karyawan akan sama yaitu 26,531. Dan selanjutnya jika seleksi bertambah

Corresponding Author: adyandardinata173@gmail.com

sebesar 1 satuan maka kinerja karyawan meningkat sebesar 0,389

2. Analisis Koefisien Korelasi, Determinasi

Hasil dari analisis koefisien korelasi dan koefisien determinasi menunjukkan tentang bagaimana keeratan hubungan dan tingkat hubungannya antara variabel seleksi (X) dengan kinerja (Y). Adapun hasil 
output SPSS 17 dapat dilihat pada Tabel 3:Koefisien Korelasi,Determinasi tabel berikut:

\section{Model Summary}

\begin{tabular}{|l|r|r|r|r|}
\hline Model & $\mathrm{R}$ & \multicolumn{1}{|c|}{ R Square } & Adjusted R Square & \multicolumn{1}{c|}{$\begin{array}{c}\text { Std. Error of the } \\
\text { Estimate }\end{array}$} \\
\hline 1 & $.487^{\mathrm{a}}$ & .237 & .222 & 3.20572 \\
\hline
\end{tabular}

a. Predictors: (Constant), Seleksi

Sumber: Data Diolah SPSS17

Dari hasil perhitungan berdasarkan SPSS17 menunjukkan nilai koefisien korelasinya (r) sebesar 0,487. Artinya bahwa variabel seleksi (X) memiliki hubungan dengan kategori yang sedang terhadap kinerja (Y). Sedangkan nilai koefisien determinasinya sebesar 0,237 atau $23,7 \%$ yang artinya bahwa tingkat hubungan antara variabel seleksi (X) terhadap variabel kinerja (Y) sebesar Tabel 4: Hasil Uji t
23,7\% sedangkan sisanya dipengaruhi oleh variabel lain yang tidak diteliti.

3. Uji t

Uji $\mathrm{t}$ digunakan untuk melihat hubungan yang signifikan antara variabel seleksi (X) terhadap kinerja (Y).Selanjutnya hasil dari uji $\mathrm{t}$ bisa dilihat dari hasil output SPSS pada tabel berikut :

\section{Coefficients $^{\mathrm{a}}$}

\begin{tabular}{|c|c|c|c|c|c|c|}
\hline \multirow{2}{*}{\multicolumn{2}{|c|}{ Model }} & \multicolumn{2}{|c|}{$\begin{array}{l}\text { Unstandardized } \\
\text { Coefficients }\end{array}$} & \multirow{2}{*}{$\begin{array}{c}\begin{array}{c}\text { Standardized } \\
\text { Coefficients }\end{array} \\
\text { Beta } \\
\end{array}$} & \multirow[b]{2}{*}{$\mathrm{T}$} & \multirow[b]{2}{*}{ Sig. } \\
\hline & & \begin{tabular}{l|l}
$\mathrm{B}$ \\
\end{tabular} & Std. Error & & & \\
\hline 1 & (Constant) & 26.531 & 3.856 & & 6.880 & .000 \\
\hline & Seleksi & .389 & .096 & .487 & 4.056 & .000 \\
\hline
\end{tabular}

a. Dependent Variable: Kinerja

Sumber: Data Diolah, SPSS17

Hasil perhitungan uji $\mathrm{t}$ didapatkan nilai sebesar 4,056, selanjutnya dilakukan perbandingan dengan nilai $t$ tabel.Untuk mendapatkan nilai $t$ tabel maka terlebih dahulu mencari derajat bebas atau degrees of freedom (df), dengan rumus ;

$\mathrm{df}=\mathrm{n}-\mathrm{k}$

dimana ;

$\mathrm{n}=$ Jumlah responden

Corresponding Author: adyandardinata173@gmail.com $\mathrm{k}=$ Jumlah variabel

$\mathrm{df}=55-2$

$\mathrm{df}=53$

Dari hasil perhitungan diatas menunjukkan bahwa nilai t hitung lebih besar dari nilai t table $(4,056>1,674)$ ,dimana $t$ tabelnya sebesar 1,674 yang di peroleh dari nilai distribusi untuk df 53 dengan $\alpha 0,05$ atau 5\% sedangkan nilai t hitungnya sebesar 4,056. Hal ini 
menunjukkan bahwa terdapat hubungan yang signifikan antara seleksi dengan kinerja karyawan pada PT. Trans Retail Indonesia Carrefour Panakukang Makassar.

Dari hasil perbandingan tersebut menunjukkan bahwa hipotesis yang diajukan dalam penelitian ini diterima dimana Ho ditolak dan menerima Ha. Hasil penelitian ini didukung oleh teori yang dikemukakan oleh Mondy (2008:162) bahwa "seleksi adalah usaha proses memilih sekelompok pelamar individu yang paling sesuai untuk posisi tertentu dalam organisasi yang harus dilakukan dengan terintegrasi sehingga bisa mendapatkan karyawanyang unggul dan berkinerja secara optimal".

\section{KESIMPULAN DAN SARAN}

\section{Kesimpulan}

Berdasarkan hasil penelitian tersebut maka dapat disimpulkan bahwa seleksi berpengaruh positif signifikan terhadap kinerja karyawan pada PT. Trans Retail Indonesia Carrefour Panakukang Makassar. Ini ditunjukkan dari nilai regresi sederhanya yakni $\mathrm{Y}=28,49+$ $0,38 X$, koefisien korelasinya sebesar 0,487 ,koefisien determinasi 0,237 $(23,7 \%)$ Selanjutnya pada pengujian hipotesis melalui uji $\mathrm{t}$ menunjukkan bahwa $t$ hitung 4,056>1,674. Dengan demikian hipotesis yang menunjukkan bahwa seleksi berpengaruh positif dan signifikan terhadap kinerja karyawan pada PT. Trans Retail Indonesia Carrefour Panakukang Makassar diterima.

\section{Saran}

Untuk meningkatkan kinerja karyawan pada PT. Trans Retail Indonesia Carrefour Panakukang Makassar sebaiknya pimpinan agar kiranya dapat selalu melakukan proses seleksi secara objektif dengan mempertimbangkan keahlian, usia, penampilan serta bakat dari calon karyawan yang akan diterima.

\section{DAFTAR PUSTAKA}

Kasmir,2017.Manajemen Sumber Daya Manusia Depok. PT. Raja Grafindo Persada.

Mangkunegara,Prabu,AA

Anwar,2016.Manajemen

Sumber Daya

Manusia.Bandung.PT.

Remaja Rosdakarya

Mondy, R. Wayne, 2008, Manajemen

Sumber Daya Manusia Jakarta.Erlangga

Sedarmayanti, 2011.Sumber Daya Manusia dan Produktivitas Kerja.Bandung.Mandar Maju

Sugiyono, 2016.Metode Penelitian Kuantitatif Kualitatif dan $R \& D$. Bandung Alfabeta. 